\title{
Exchange Rate Pass-Through, Markups, and Inventories
}

\author{
Adam Copeland and James A. Kahn ${ }^{1}$
}

December 2011 (Preliminary)

${ }^{1}$ Copeland: The Federal Reserve Bank of New York (adam.copeland@ny.frb.org); Kahn: Yeshiva University (james.kahn@yu.edu). The views expressed in this paper are those of the author and do not necessarily reflect the views of the Federal Reserve Bank of New York or the Federal Reserve System. 


\begin{abstract}
This paper examines the response of inventories to changes in markups induced by exchange rate fluctuations. The stockout-avoidance model of inventory behavior suggests that inventory-sales ratios should be strongly related to markups. Since markups are difficult to measure, much less changes in markups, this has been a difficult implication to examine. It is well known that exporters do not fully adjust their prices across countries in response to exchange rate movements, at least in the short run. Instead, they appear to absorb a substantial amount of variation in their profit margins. Thus persistent exchange rate movements provide a natural experiment by which to test this key implication of the stockout-avoidance model. We find evidence that inventory-sales ratios of imported vehicles do respond positively to real appreciation of the dollar, consistent with the idea that the appreciation positively affects markups.
\end{abstract}


This paper examines the response of inventories to changes in markups induced by exchange rate fluctuations. The stockout-avoidance model of inventory behavior suggests that inventory-sales ratios should be strongly (and positively) related to markups. This is in contrast to other approaches to inventory modeling in which markups play little or no role. Since markups are difficult to measure, much less changes in markups, this has been a difficult implication to examine. ${ }^{1}$

A large literature has explored a variety of explanations for "incomplete pass-through" — the fact that exporters apparently fail to adjust their prices across countries fully in response to exchange rate movements, at least in the short run. In essence, the question is why a firm selling an otherwise identical good in two countries with different currencies allows the relative price of the good in a common currency to vary with the exchange rate between the two countries. While some explanations have reduced the magnitude of the puzzle-for example, by quantifying the portion of value added in the destination country - there remains the residual that suggests firms absorb fluctuations in their price-cost markups induced by exchange rates. ${ }^{2}$

If inventory-sales ratios do indeed vary with markups (see Bils and Kahn, 2000, for supporting evidence), then exchange rate-induced changes in markups, while not directly observable, ought to result, ceteris paribus, in movements in inventory-sales ratios. Thus, whereas markups are difficult to observe directly, we may see indirect evidence through inventory behavior. On the other hand, to the extent firms use inventories along with prices to compete for customers, it is possible that whatever forces are responsible for incomplete passthrough could also result in unresponsive inventory-sales ratios. Consequently, it is desirable to have a model in which both markups and inventory-sales ratios are endogenously

\footnotetext{
${ }^{1}$ Bils and Kahn (2000) show a striking example of this phenomenon using tobacco industry data from the 1990s.

${ }^{2}$ Early work on this subject includes Mann (1987), Krugman (1987), Hooper and Mann (1989), Froot and Klemperer (1989), Marston (1990). Goldberg and Verboven (2001) examines the European automobile industry. Goldberg and Knetter (1997) provide an overview of early passthrough literature. More recently, Hellerstein (2008) examines the beer industry and finds that roughly half of incomplete passthrough is accounted for by markup adjustments.
} 
determined. We provide such a model in Section I, and illustrate it through dynamic simulations. Section 2 describes automobile industry data that we then use in a "differencein-differences" style estimation of the impact of exchange rates on inventory-sales ratios. On balance we are able to find effects of the correct sign - that is, an appreciation of the dollar against the home currency of automobile exporters to the U.S. results in an increase in the U.S. inventory-sales ratio for the exporter (relative to the inventory-sales ratios of U.S. firms). Thus the results are generally consistent with the idea that exchange rate movements affect markups, which are in turn reflected in movements in inventory-sales ratios.

\section{Durable Goods Production, Sales, and Inventory}

This section introduces the model that we will use to describe the equilibrium response of a durable goods-producing industry to various shocks. It is a partial equilibrium model, since the focus is one industry. that produces a variety of goods. We derive consumer demand based on utility maximization, but add stochastic aggregate and idiosyncratic shocks. To make the model tractable, we assume that at each date $t$, consumers rent a continuum of durables $x_{t}(i), i \in[0,1]$ for a price $p_{t}(i)$ from monopolistically competitive retailers. Each retailer purchases a quantity of a generic durable good from perfectly competitive manufacturers, and costlessly transforms it into a specific good which it adds to its inventory. Rented goods depreciate at rate $\delta$, while goods in inventory do not depreciate.

In the context of an exporting firm, we can think of the "retailer" as a subsidiary of the manufacturing firm. It purchases the durable good in the manufacturer's home country, and then exports it to the United States. Thus it pays a cost in the home country's currency but obtains revenue in dollars, and therefore is subject to exchange rate risk if the U.S. price (or its own cost) fails to move one-for-one with the exchange rate.

While this framework is necessary because of the technical difficulties associated with monopolistic pricing of durable goods, it does raise the question of what exactly are "in- 
ventories" and "sales" in this context. Let $x_{t}$ denote the stock of durables in consumers' possession at date $t$ (in the model, this is the total amount of rentals). Let $I_{t}$ denote the stock of retail inventories left at the end of period $t$, and let $q_{t}$ denote orders of goods by the retailers that arrive during period $t$.

Given the definition of $x_{t}$, a natural definition of "sales" $s_{t}$ would be

$$
s_{t} \equiv x_{t}-x_{t-1}(1-\delta),
$$

that is, the gross increase in the stock from $t-1$ to $t$. Inventories $I_{t}$, defined as unsold (in this case, unrented) goods as of the end of period $t$, would then obey the usual identity

$$
I_{t}=I_{t-1}+q_{t}-s_{t}
$$

As in Kahn $(1987,1992)$ and Bils and Kahn (2000), we will focus on the "stock available" to consumers as of period $t, A_{t}$, from which $x_{t}$ or $s_{t}$ is chosen. We assume that this includes $q_{t}$. With durable goods, there is some ambiguity in this concept, as it may or may not include the stock of existing (or "used") goods. For example, is the relevant inventory of houses the entire housing stock, including newly built but unsold houses as well as those currently occupied? Just the former? Or the unsold newly built plus those existing homes designated as "for sale" (a rather nebulous concept). Primarily for convenience we will adopt the more expansive (or "gross" stock) view, and define $A_{t}$ as $I_{t-1}+q_{t}+(1-\delta) x_{t-1}$. Thus we can think of the total stock of durables (new and used) in the hands of consumers, $x_{t}$, as being chosen from $A_{t}$, as opposed to the "net" concept of $s_{t}$ being chosen from $I_{t-1}+q_{t} \cdot{ }^{3}$ The stock available $A_{t}$ then evolves according to

$$
A_{t}=A_{t-1}+q_{t}-\delta x_{t-1}
$$

\footnotetext{
${ }^{3}$ Depending on the industry, one or the other may be more realistic. The "gross" definition is most appropriate for goods with high turnover: Rental cars, hotel rooms, perhaps apartments. We adopt it mainly for tractability.
} 


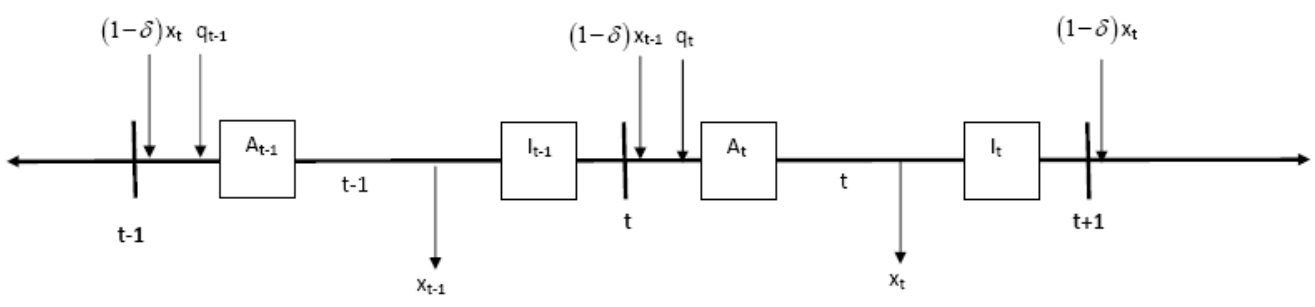

Figure 1: Timeline

Figure 1 illustrates the timeline behind these definitions.

\subsection{Consumers}

Following Bils and Kahn (2000), we will assume that the stock $A_{t}$ interacts smoothly with the choice of $x_{t}$ - that $A_{t}$ provides a service that affects the marginal utility consumers get from $x_{t}$. This could be, for example, from greater selection, so that the consumer can get closer to his preferred variety, or better information from being able to see the product. At the same time, the specification permits the possibility, as a limiting case, of pure stockoutavoidance, where the consumer obtains the minimum of $x_{t}$ and $A_{t}$. In particular, we have in mind that each good may come in a variety of sizes or colors, and that the larger the inventory the better "fit" with the consumers' needs.

We represent this relationship between the effective service level $h$, the quantity of the good $x$, and the available stock $A$ by a CES function

$$
h\left(x_{t}(i), A_{t}(i)\right)=\left[(1-\phi) x_{t}(i)^{1-\gamma}+\phi A_{t}(i)^{1-\gamma}\right]^{1 /(1-\gamma)} .
$$

Since (4) is a key assumption, it is worth justifying. One way to see it is as a generalization of the stockout-avoidance model where actual sales equal the minimum of $x$ and $A$. This 
specification has a similar characteristic as $\gamma$ goes to infinity. With $\phi=0.5$ we would essentially have $h=\min \{x, A\}$ in the limiting case. At the other extreme, it is possible that $A$ and $x$ could be substitutes; a high degree of availability could reduce the need to buy or rent $x$, much as automatic teller machines reduce the demand for money. In fact, as we shall see, the least interesting case is $\gamma=1$.

We let $H$ denote a Dixit-Stiglitz (1977) composite of the underlying goods. There are also other goods summarized by a composite $z_{t}$ with a constant price that we will normalize to one. The consumer solves the following maximization problem given $\left\{p_{t}(i), A_{t}(i)\right\}$ :

$$
\max E_{t}\left\{\sum_{\tau=t}^{\infty} \beta^{\tau-t}\left[(1-1 / \sigma)^{-1} H_{\tau}^{1-1 / \sigma}+u\left(z_{\tau}\right)\right]\right\}
$$

where

$$
H_{t} \equiv\left[\int h\left(x_{t}(i), A_{t}(i)\right)^{1-1 / \rho} d i\right]^{\rho /(\rho-1)}
$$

subject to

$$
W_{t}=W_{t-1}\left(1+r_{t}\right)+y_{t}-\int p_{t}(i) x_{t}(i) d i-z_{t}
$$

where $W_{t}$ is wealth at the end of period $t, r_{t}$ is the rate of return, and $y_{t}$ is income.

The first-order condition for $x_{t}(i)$ is

$$
H_{t}^{-\sigma}\left(\frac{H_{t}}{h\left(x_{t}(i), A_{t}(i)\right)}\right)^{1 / \rho}\left(\frac{h\left(x_{t}(i), A_{t}(i)\right)}{x_{t}(i)}\right)^{\gamma}(1-\phi)=\lambda_{t} p_{t}(i)
$$

where $\lambda_{t}$ is the shadow price of the budget constraint at $t$, using the fact that

$$
\frac{\partial h}{\partial x}=(h / x)^{\gamma}(1-\phi)
$$

This yields, for the marginal rate of substitution between goods $i$ and $j$ (suppressing the $t$ 
subscript and using the shorthand $h(i)$ for $h(x(i), A(i)))$ :

$$
\left(\frac{h(i)}{h(j)}\right)^{-1 / \rho}=\frac{p(i)}{p(j)}\left(\frac{h(i) / x(i)}{h(j) / x(j)}\right)^{-\gamma} .
$$

This modifies the relative price of $i$ and $j$ by the inverse of the marginal impact on the actual service flow $h$. If $\phi=0$ then $h / x=1$ and the term multiplying the relative price goes away, as it does if $\gamma=0$.

Following Dixit-Stiglitz, we can define

$$
\begin{aligned}
v(i) & =p(i)(h(i) / x(i))^{-\gamma} \\
V & =\left[\int v(i)^{1-\rho} d i\right]^{1 /(1-\rho)} .
\end{aligned}
$$

Then we have

$$
h(i)=H\left(\frac{v(i)}{V}\right)^{-\rho}
$$

Here we will make the standard Dixit-Stiglitz assumption that agents ignore the impact of changes in $x(i), p(i)$, or $A(i)$ on $V$. Of course, this is not an explicit expression for $x(i)$ as a function of $p(i)$ and $A(i)$, but it does define an implicit relation that will serve as a "demand curve" for retailers.

In a symmetric equilibrium, $h(i)=H$ and $v(i)=V$. We therefore have

$$
\begin{aligned}
\xi & \equiv \frac{\partial x / x}{\partial A / A}=\frac{(\gamma \rho-1)(v / V)^{-\rho}(h / A)^{\gamma-1} \phi}{\gamma \rho(h / H)-(\gamma \rho-1)(v / V)^{-\rho}(h / x)^{\gamma-1}(1-\phi)} \\
& =\frac{(\gamma \rho-1) \phi(h / A)^{\gamma-1}}{\gamma \rho-(h / x)^{\gamma-1}(1-\phi)(\gamma \rho-1)}
\end{aligned}
$$

So sales will depend positively on inventories if $\gamma \rho>1$. If $\gamma>\rho$ the primary reason is that higher $A(i)$ makes $x(i)$ more attractive, as the consumer does not like the ratio to vary. If $\rho>\gamma$, the primary reason is that higher $A(i)$ induces substitution from other goods toward good $i$. 
For the price elasticity we have

$$
\begin{aligned}
\epsilon & \equiv-\frac{\partial x / x}{\partial p / p}=\frac{\rho(h / H)}{\gamma \rho(h / H)-(\gamma \rho-1)\left(\frac{v}{V}\right)^{-\rho}(h / x)^{\gamma-1}(1-\phi)} \\
& =\frac{\rho}{\gamma \rho-(h / x)^{\gamma-1}(1-\phi)(\gamma \rho-1)}
\end{aligned}
$$

Note that $h / x$ is positively related to $A / x$, the inventory-sales ratio. Consequently, again assuming $\gamma \rho>1, \epsilon$ is increasing in $A / x$ if $\gamma>1$, and decreasing in $A / x$ if $\gamma<1$. If $A / x$ is countercyclical (as it is in the data), then the markup is procyclical if $\gamma>1$, countercyclical if $\gamma<1$, and constant if $\gamma=1$. We will focus on the case $\gamma<1$ and $\rho>1 / \gamma$.

Income or wealth uncertainty makes $\lambda_{t}$, and hence $H_{t}$, stochastic. In a symmetric equilibrium (where $h_{t}=H_{t}$ ), (8) becomes

$$
h_{t}^{-\sigma}\left(\frac{h_{t}}{x_{t}}\right)^{\gamma}(1-\phi)=\lambda_{t} p_{t}
$$

This suggests that an increase in $p_{t}$ holding $\lambda$ (inversely related to wealth) fixed would cause both $H_{t}$ and $x_{t}$ to fall, but $x_{t}$ would fall by more. On the other hand, a pure wealth effect (an increase in $\lambda_{t}$ ) would cause $H_{t}$ and $x_{t}$ to fall in proportion. While a full solution for $\lambda$ would require a general equilibrium model, we can capture the essential implications of (??) as follows. Suppose

$$
\begin{aligned}
& h_{t}=\lambda_{t}^{-1 / \sigma} \\
& x_{t}=\lambda_{t}^{-1 / \sigma}\left(\frac{1-\phi}{p_{t}}\right)^{1 / \gamma}
\end{aligned}
$$

What the partial equilibrium framework cannot determine is the relationship between $p_{t}$ and $\lambda_{t}$, i.e. the wealth effect of changes in $p_{t}$. We parameterize this as

$$
\lambda_{t}=\kappa_{t} p_{t}^{\psi}
$$


where $\kappa_{t}$ is an exogenous stochastic process with a mean of one, and $p_{t}$ is the endogenous equilibrium common rental price of each durable good $i$.

So to summarize, $\epsilon$ is the own price elasticity of $x(i)$ with respect to $p(i)$, holding fixed $A(i)$ and all other prices and inventory stocks. $1 / \gamma$ is the " $\lambda$ constant" elasticity of aggregate $x$ with respected to the aggregate price $p$ when the consumer is compensated so that $\lambda_{t}$ (and hence $\left.H_{t}\right)$ remains the same. Finally, $-(1+\psi) / \gamma$ is the uncompensated elasticity of $x$ with respect to $p$.

It is worth emphasizing a key feature of the model: The interaction of inventories with demand results in a variable elasticity in a natural way, and hence variable markups. Earlier work (Bils and Kahn, 2001) emphasized the role of time-varying markups in accounting for cyclical dynamics, but did not have a model of markups, and the literature has few other examples. Also, the model is perfectly adaptable to the case of nondurable goods, simply by setting $\delta=1$, and retains the same features, just with different dynamic responses to shocks.

\subsection{Retailers}

Retailers purchase generic durable goods and hold them in stock for consumers to rent. We can assume a continuum of retailers indexed by $i$. Each retailer costlessly transforms the generic durable good into a unique good indexed by $i$. Given a price process for the generic durable $\left\{\pi_{t}\right\}$ and a stock of goods carried over from $t-1, A_{t-1}(i)-\delta x_{t-1}(i)$, retailer $i$ chooses to purchase $q_{t}(i)$ goods from producers and to charge price $p_{t}(i)$ to solve the problem

$$
\max E_{t}\left\{\sum_{\tau=t}^{\infty} \beta_{t, \tau}\left[p_{\tau}(i) x_{\tau}(i)-e_{t}^{-1} \pi_{\tau} q_{t}(i)\right]\right\}
$$

subject to

$$
A_{t}(i)=A_{t-1}(i)+q_{t}(i)-\delta x_{t-1}(i)
$$


and to the implicit demand for $x_{t}(i)$ derived in the previous section, where $\beta_{t, \tau}$ is the $\tau$ period ahead discount factor at date $t$ and $e_{t}$ is the exchange rate expressed as the exporter's currency per dollar (that is, an increase in $e$ is an appreciation of the dollar). Thus the choice of $q$ is equivalent to the choice of $A$. In what follows we will suppress the subscripts on $\beta$, as we will be assuming a constant real interest rate.

As is standard in models with inventories and demand uncertainty, we will assume that $q_{t}$ and $p_{t}$ are chosen knowing $\pi_{t}$, but without knowing the realization of $x_{t}(i)$, which will be affected by demand shocks. The first-order condition for that choice is

$$
\begin{aligned}
E_{t}\left\{p_{t}(i) \frac{\partial x}{\partial A}-e_{t}^{-1} \pi_{t}+\beta_{t, t+1} e_{t+1}^{-1} \pi_{t+1}\left(1-\delta \frac{\partial x}{\partial A}\right)\right\} & = \\
E_{t}\left\{p_{t}(i) \xi_{t} \frac{x_{t}}{A_{t}}-e_{t}^{-1} \pi_{t}+\beta_{t, t+1} e_{t+1}^{-1} \pi_{t+1}\left(1-\delta \xi_{t} \frac{x_{t}}{A_{t}}\right)\right\} & =0 .
\end{aligned}
$$

This is similar in form to the condition in Bils and Kahn (2000), but the dependency of $x$ on $A$ here is derived from utility maximization rather than posited directly. (Also, Bils and Kahn assumed $\delta=1$.) As for price, we have a condition similar to the standard monopolistic pricing formula, modified by consideration of uncertainty, durability, and inventories:

$$
E_{t}\left\{x_{t}\left[p_{t}\left(\epsilon_{t}-1\right)-\epsilon_{t} \beta_{t, t+1} \delta e_{t+1}^{-1} \pi_{t+1}\right]\right\}=0
$$

where $\epsilon_{t} \equiv-\left(p_{t} / x_{t}\right) \partial x_{t} / \partial p_{t}$ is assumed to exceed one. As we have seen, in general it will vary over time with the level of $A / x$. Price is set relative to discounted one-period-ahead cost because that is the replacement cost for a good sold out of inventory. And because the good is durable and only rented, the cost is deflated by $\delta<1$. Note that if $x_{t}$ were known when $p_{t}$ is chosen, we would have the familiar result that the markup (defined as $\left.m_{t} \equiv p_{t} /\left(\beta_{t, t+1} \delta e_{t+1}^{-1} \pi_{t+1}\right)\right)$ is $\epsilon_{t} /\left(\epsilon_{t}-1\right)$, and in fact this is still the case to a first-order approximation. But the elasticity itself, as we have seen, depends on the inventory-sales ratio through the dependence of $x$ on $A$. 
More important for the focus of this paper, the condition for optimal inventory behavior (15) can be written (similarly to Bils and Kahn, 2000) as follows:

$$
E_{t}\left\{\frac{\beta_{t, t+1} e_{t} \pi_{t+1}}{e_{t+1} \pi_{t}}\left[1+\delta\left(m_{t}-1\right) \xi_{t} \frac{x_{t}}{A_{t}}\right]\right\}=1
$$

This implicitly expresses the inventory-sales ratio as a function of two terms: one related to intertemporal substitution, $\beta_{t, t+1} e_{t} \pi_{t+1} /\left(e_{t+1} \pi_{t}\right)$, essentially a real interest rate; and $m_{t}$, the markup. Given the highly persistent nature of exchange rates (both real and nominal), it is likely that the primary impact of movements in $e_{t}$ on the inventory-sales ratio is through the markup. $^{4}$

Simulations indicate that steady state $A / x$ is increasing in both $\gamma$ and $\rho$ (at least for $\gamma<1, \rho \gamma>1)$, i.e. as $A(i)$ and $x(i)$ become less substitutable, and as the different service flows $H(i)$ become more substitutable. Intuitively, retailer $i$ will hold more inventory of good $i$ the more it enhances the attractiveness of $x(i)$ to the consumer, and the more willing the consumer is to substitute other varieties for $i$. The price elasticity of $x$ increases with $\rho$ and decreases slightly with $\gamma$. The steady state price elasticity is increasing in $\rho$, not surprisingly, but slightly decreasing in $\gamma$. Presumably the latter occurs because $A / x$ is increasing and $\gamma<1$

Given (10) and (15) it is clear that demand shocks taking the form of multiplicative shifts in the expected value of $H_{t}$ will, holding prices fixed, increase each $x(i), A(i)$, and hence $h(i)$ by the same factor as the change in $H$. There is no direct impact on the elasticity of demand $\epsilon_{t}$ or on $\partial x / \partial A$. Any changes in these variables result from changes in the other elements of conditions (12) and (13) - for example, changes in production costs or interest rates.

Since this is a partial equilibrium model, we treat $\pi_{t}$ and $\beta_{t, t+1}$ as exogenous. For

\footnotetext{
${ }^{4}$ Bils and Kahn (2000) argued that the first factor plays a negligible role in explaining movements in inventory-sales ratios, at least cyclically, because the intertemporal substitution term is not very forecastable. Consequently, the cyclical behavior of inventory-sales ratios, they argue, is best explained by countercyclical markups.
} 
simplicity we will assume interest parity, so that the effective real rate is the same across countries. We will assume $\pi_{t}$ is positively related to the level of aggregate orders $q_{t}$ relative to some "trend" level of output $\bar{q}_{t}$ :

$$
\pi_{t}=\left(q_{t} / \bar{q}\right)^{\theta}
$$

where $\bar{q}$ is the steady state level of $q$. Note that retailers are price takers, but use (17) in forming expectations of $\pi_{t+1}$.

Finally, we can deflate all nominal variables by price indexes so that we $p_{t}, \pi_{t}$, and $e_{t}$ are in real terms. For the purposes of simulating the impact of exchange rate movements we will assume that the real exchange rate follows a highly persistent $\mathrm{AR}(1)$ process:

$$
\ln e_{t}=\chi \ln e_{t-1}+u_{t}
$$

Thus in this approach a shock to the exchange rate is identical to a persistent idiosyncratic cost shock, to which the retailer and manufacturer will optimally adjust price, production, and inventory decisions.

Now we have the following system, adjusted to be in a common currency:

$$
\begin{aligned}
h_{t} & =\left[(1-\phi) x_{t}^{1-\gamma}+\phi A_{t}^{1-\gamma}\right]^{1 /(1-\gamma)} \\
\kappa_{t} p_{t}^{1+\psi} & =h_{t}^{-\sigma}\left(h_{t} / x_{t}\right)^{\gamma}(1-\phi) \\
A_{t} & =A_{t-1}+q_{t}-\delta x_{t-1} \\
0 & =E_{t}\left\{x_{t}\left[p_{t}\left(\epsilon_{t}-1\right)-\epsilon_{t} \beta \delta \pi_{t+1}\right]\right\} \\
0 & =E_{t}\left\{p_{t} \xi_{t} \frac{x_{t}}{A_{t}}-e_{t}^{-1} \pi_{t}+\beta e_{t+1}^{-1} \pi_{t+1}-\beta \delta e_{t+1}^{-1} \pi_{t+1} \xi_{t} \frac{x_{t}}{A_{t}}\right\} \\
\epsilon_{t} & \equiv \frac{\rho}{\gamma \rho-\left(h_{t} / x_{t}\right)^{\gamma-1}(1-\phi)(\gamma \rho-1)} \\
\xi_{t} & =\frac{(\gamma \rho-1) \phi\left(h_{t} / A_{t}\right)^{\gamma-1}}{\gamma \rho-\left(h_{t} / x_{t}\right)^{\gamma-1}(1-\phi)(\gamma \rho-1)}=\epsilon_{t}(\gamma-1 / \rho) \phi\left(h_{t} / A_{t}\right)^{\gamma-1} \\
\pi_{t} & =\left(q_{t} / \bar{q}\right)^{\theta} \\
\ln e_{t} & =\chi \ln e_{t-1}+u_{t}
\end{aligned}
$$


Before solving the equilibrium we need to make more specific assumptions about what is known when the retailers make pricing and inventory decisions. We will assume that in choosing date $t$ variables they know the wholesale cost $\pi_{t}$ in their own currency, but make production and inventory decisions prior to knowing the exchange rate. Because of these assumptions we need to introduce several additional artificial variables: $\pi_{t}^{*} \equiv \pi_{t+1}$, $p_{t}^{*} \equiv p_{t+1}, A_{t}^{*} \equiv A_{t+1}$, and $q_{t}^{*}=q_{t+1}$. So, for example, at date $t$ the retailer will choose $p_{t}^{*}$ (i.e. $\left.p_{t+1}\right)$ knowing all $t$-dated variables including $\pi_{t}^{*}$ and $e_{t}$ but not $e_{t+1}$.

\subsection{Simulation Results}

As we have seen, if $\gamma<1$ a higher $A / s$ ratio results in a higher elasticity of demand, so the firm will reduce its markup. A negative shock to $e_{t}$ raises cost in dollars, so we would expect a decrease in inventory-sales ratios and price increases that do not fully offset the increase in costs. The price response will depend on the change in the elasticity of demand.

With this intuition in mind, we have simulated the model's response to a persistent negative shock to $e$. The parameters are listed in Table $1 . \phi$ was chosen to mimic the inventory-sales ratio in the data. The remainder were simply set at a priori plausible values. Future work will consider different estimation or calibration strategies.

Table 1

\begin{tabular}{ccccccc}
$\gamma$ & $\rho$ & $\theta$ & $\phi$ & $\beta$ & $\delta$ & $\chi$ \\
\hline 0.75 & 3 & 0.004 & 0.173 & 0.995 & 0.015 & 0.95 \\
\hline
\end{tabular}

To get an observable counterpart of $A_{t} / x_{t}$, let $a_{t} \equiv A_{t}-x_{t-1}(1-\delta)$. Then $a_{t}=$ $I_{t-1}+q_{t}$, which corresponds to the "stock available" as in Kahn (1987) or Bils and Kahn (2000). We would expect $a_{t} / s_{t}$ to have similar high frequency properties to $A_{t} / x_{t}=$ $\left(a_{t}+x_{t-1}(1-\delta)\right) /\left(s_{t}+x_{t-1}(1-\delta)\right)$ given that $x_{t}$ is a large stock that likely does not deviate much from trend.

Figure 2 shows the responses of key variables. Note that initial responses reflect delays, as price, production, and even sales decisions are made in advance of observing the shock to 
e. The first panel shows the impact on price, costs, and the markup. The initial impact on cost $\pi$ is just the inverse of the exchange rate shock because production is pre-determined, but then cuts in production mitigate the impact. Price rises by less than cost, and the markup declines The degree of pass-through varies, but appears to be on the order of one-half.
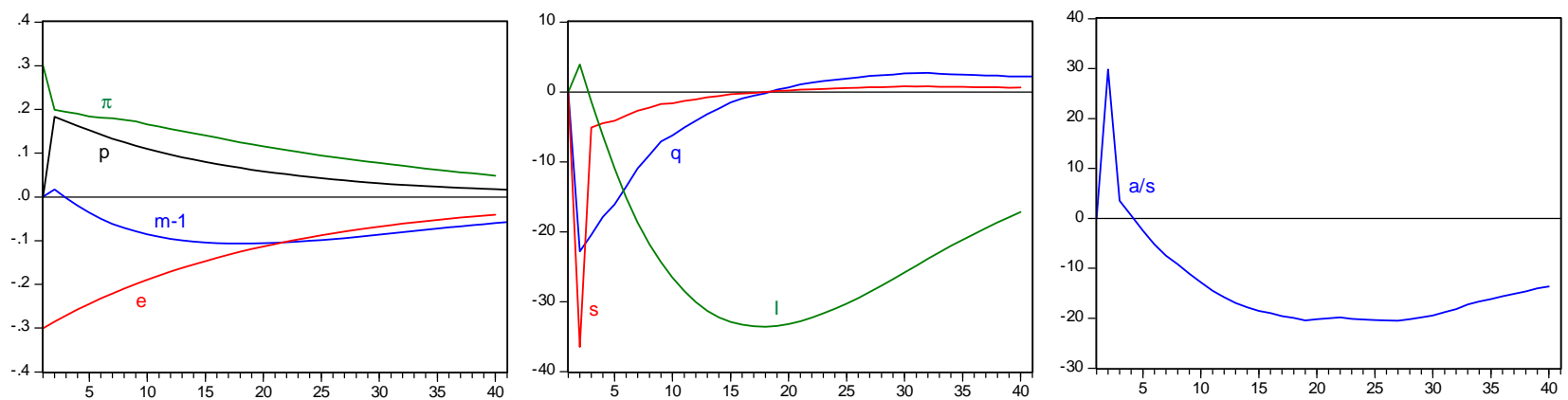

Note:Units are $100 \times \log$ deviations from the steadystate, i.e. approximatelypercentag e deviations

Figure 2: Responses to a Dollar Depreciation

The other panels depict the quantity responses. These are qualitatively plausible but far too large. For example, the 0.3 percent depreciation of the dollar results in initial declines in production and sales of more than 20 percent. The $a / s$ ratio initially rises by about 30 percent. Some of these magnitudes are because of the choice of parameters, and some are because of the timing assumptions and the lack of more convex adjustment costs. But qualitatively they suggest that initially the $a / s$ ratio may go the "wrong" way initially, but before long it declines along with the markup.

\section{Data and Estimation Results}

\section{$2.1 \quad$ Prices}

We briefly examine proprietary transaction price data obtained from JD Power and Associates. These are monthly average transaction prices for U.S. sales by model year. We con- 
struct indexes of such prices by country of origin (Germany (GE), Japan (JP), S. Korea (SK), and N. America (NA)), and then regressed $\log \left(P_{j t} / P_{t}\right)$ on $\log \left(e_{t}\right)$, where $j=G E, J P, S K$, and $P_{t}$ is the index for $N A$ cars. Here $e_{t}^{n o m}$ is the nominal exchange rate in terms of the dollar. This does not capture many factors that might affect passthrough (imported material shares, destination value added, marginal production cost). In particular, we are handicapped by not having data on multiple destinations. Nonetheless, it does at least give some statistical information about price responsiveness. If passthrough were 100 percent, we would expect a coefficient of -1 , whereas if there is no passthrough at all, the coefficient would be zero. We find a coefficient of -0.461 , with a standard error of 0.041 . This suggests passthrough of somewhat less than 50 percent, which is broadly consistent with what others have found.

\subsection{Quantities}

We have collected monthly data on U.S. inventories and sales for automobiles from four countries of origin: Germany, Japan, South Korea, and the U.S. itself. We also have (confidential) data on transactions prices. To match the latter, we have assembled the data to cover the period from January 1999 to November 2007. While the data are available at the level of individual models, because of the entry and exit of models, and problems associated with models that have very low sales in given months, we have aggregated the data to the level of total U.S. sales and inventories by country of origin. We have also collected monthly nominal exchange rate and consumption price deflators for the four countries from the St. Louis Fed's FRED database.

In principle we can estimate the parameters of the model, as we have done in another paper (Kahn and Copeland, 2011). While many of the key variables in the model such as $A$ and $x$ are not directly measured (or at least not well enough for the purposes of this paper) because they include the stock of used vehicles, we can nonetheless estimate the model based on the behavior of observable counterparts $I_{t}$ and $s_{t}$. This paper's more narrow focus and 
the structure of the data lead us to adopt a less parametric approach.

Figure 3 shows the actual $a / s$ ratios by country of origin, along with the the relative ratios. The $a / s$ ratios appear to comove fairly closely, though a lot of that may be seasonal in nature. The relative ratios would largely eliminate common seasonal movements but nonetheless also exhibit some comovement
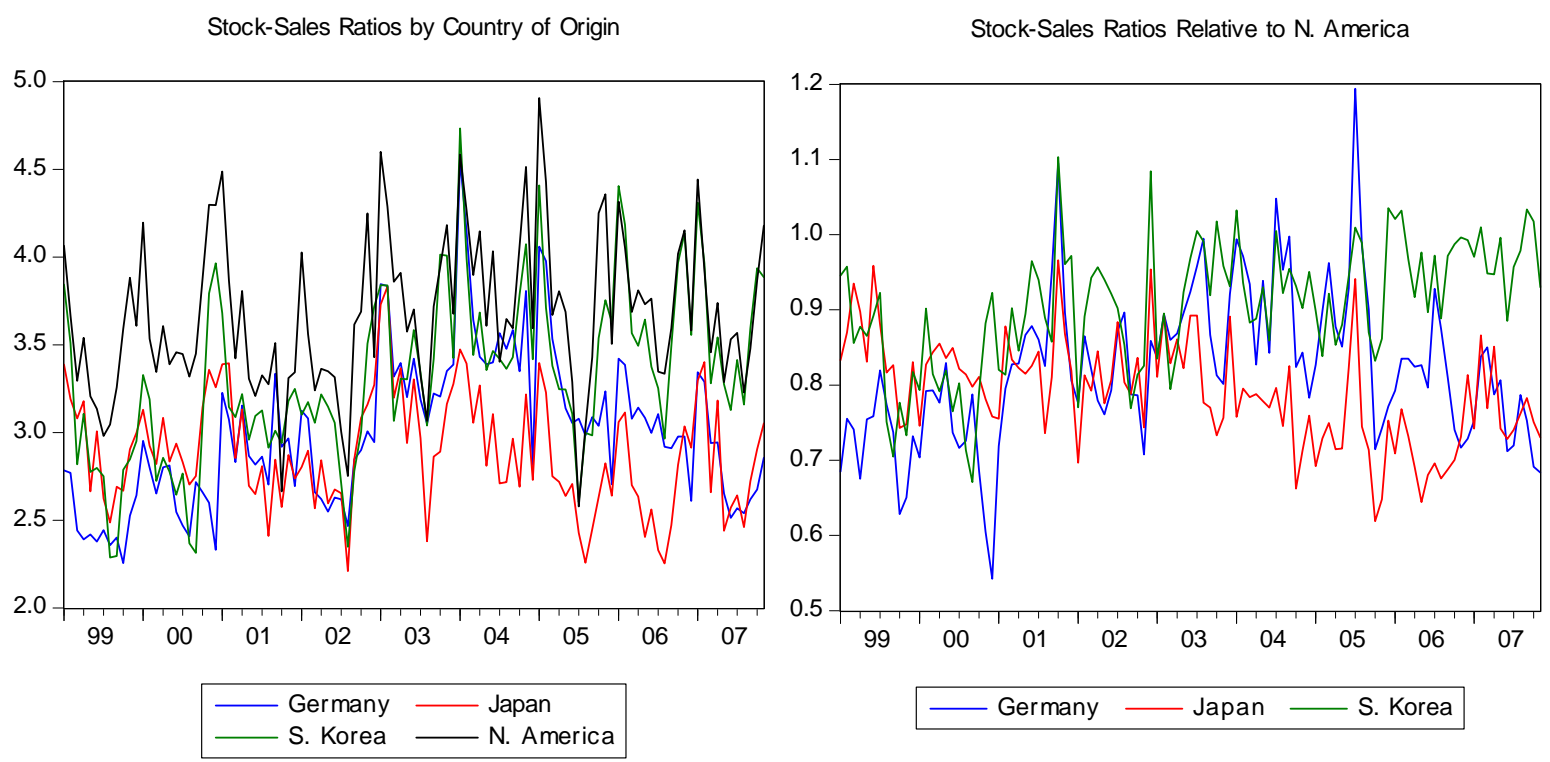

Figure 3: Stock-Sales Ratios

Figure 4 shows our real exchange rate series. Not surprisingly, they look very similar to the nominal exchange rate series, albeit with slightly different trends. 
Real Exchange Rates Relative to U.S.

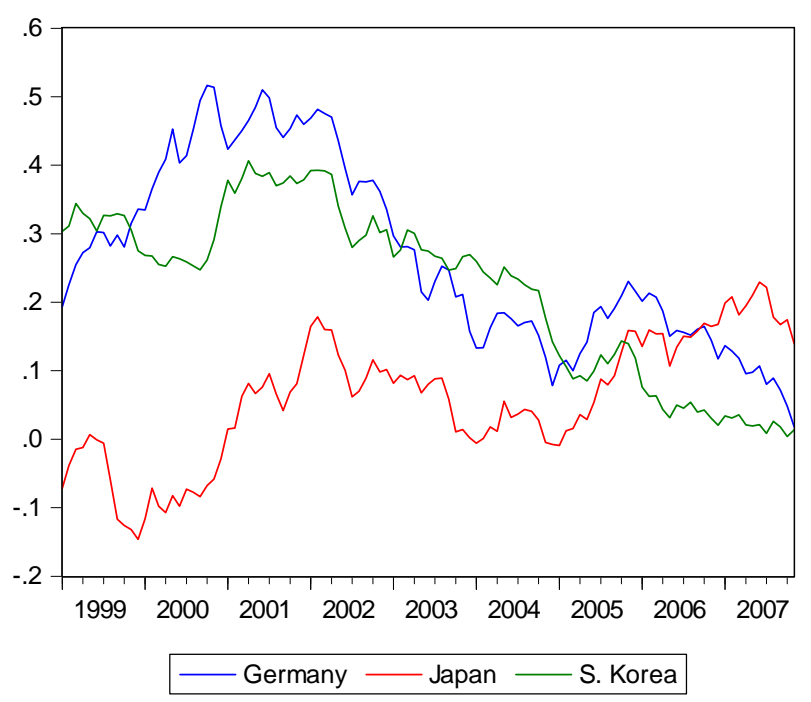

Figure 4: Real Exchange Rates

Given that in the short samples there are slight trends in the dependent variable (perhaps due to composition effects), the presence of trends in the real exchange rate series is obviously problematic for the estimation, as the focus here is on higher frequency movements. Since explaining the trends is outside the scope of this paper, we will simply include separate time trends in our regressions.

We use a difference-in-difference style specification, looking at the impact of real exchange rate movements on relative inventory-sales ratios. That is, let $R A S_{i t}$ denote the $a / s$ ratio for automobiles originating in country $i$ relative to that for automobiles originating in the U.S., and let $R E X_{i t}$ denote the real exchange rate $e_{t}=E_{t} P_{t} / P_{i t}$, where $E_{t}$ is the nominal rate in foreign currency per dollar, $P_{t}$ a U.S. price index, and $P_{i t}$ a price index for country $i$. We estimate equations of the form

$$
\log \left(R A S_{i t}\right)=\alpha_{i}+b_{i} \log \left(R E X_{i t-k}\right)+c_{i} t+u_{i t}
$$


for various values of $k$ or

$$
\log \left(R A S_{i t}\right)=\alpha_{i}+b_{i} \log \left(R E X_{i t}\right)+c_{i} t+u_{i t}
$$

where we instrument for $\log \left(R E X_{i t}\right)$ using lagged values. We allow for fixed effects because markups or vehicle characteristics may differ systematically by country of origin.

The regression results for various specifications are shown in Table 2. All results include fixed effects for country of origin and separate trends. Otherwise, we consider various lags of $R E X$ (where $k=0$ implies instrumental variables), to allow for the unknown lag between the observation of exchange rate movements on the one hand, and pricing and shipment decisions get made. We also test the constraint that the coefficients on $\log (R E X)$ are the same and fail to reject it at the 5 percent significance level.

Table 2: Regression Results

\begin{tabular}{cccccc}
$k$ & $b$ & $b_{G E}$ & $b_{J P}$ & $b_{S K}$ & $R^{2}$ \\
\hline 1 & 0.142 & - & - & - & 0.383 \\
& $(0.072)$ & & & & \\
\hline 1 & - & -0.008 & 0.267 & 0.345 & 0.393 \\
& & $(0.098)$ & $(0.148)$ & $(0.144)$ & \\
\hline 0 & 0.151 & - & - & - & 0.386 \\
& $(0.076)$ & & & & \\
\hline 2 & 0.167 & - & - & - & 0.386 \\
& $(0.070)$ & & & & \\
\hline 3 & 0.190 & - & - & - & 0.390 \\
& $(0.069)$ & & & & \\
\hline
\end{tabular}

Thus the results show a significant positive impact of an appreciation of the dollar on inventory-sales ratios of imported vehicles, consistent with the idea that the appreciation 
results in increased markups. The effect gets slightly stronger and more significant with longer lags.

Note that using the real exchange rate at least controls for changes in nominal production costs due to inflation or deflation. For example, if the Yen appreciates relative to the dollar because of deflation in Japan, presumably nominal marginal cost declines at the rate of deflation as well, so there would be no real impact on markups from leaving the U.S. price unchanged. In any case, regression results using the nominal exchange rates were very similar to those in Table 2.

A $b$ coefficient of 0.15 means that, for example, a 10 percent real appreciation of the dollar results in a 1.5 percent increase in $a / s$. That is an order of magnitude smaller than we find in the model simulations, but also more plausible. Among other things, exchange rate movements may be more persistent in the data than we assumed in the model, which implies a smaller role for intertemporal substitution. In the model the AR(1) process for the exchange rate implies relatively rapid mean reversion, whereas in the data exchange rates are more like unit root processes.

\section{Conclusions}

This paper finds evidence that exchange rate movements are associated with movements in markups by looking at the responses of inventory-sales ratios. The so-called stockoutavoidance model of inventories implies that inventory-sales ratios will be strongly affected by markups, and previous research has suggested that at least at business cycle frequencies,

changing markups are the primary factor influencing the ratios. Using data on U.S. automobile sales and inventories by country of origin, we find strong evidence that exchange rate movements affect inventory-sales ratio consistent with the idea that incomplete passthrough is associated with changing markups. We also provide a model of the joint determination of prices, markups, production, and inventories, simulations of which provide some qualitative 
support for the empirical findings, although more work needs to be done on calibrating or estimating the parameters to match the quantititive movements. 


\section{References}

[1] Bils, Mark, and James Kahn. 2000. "What Inventory Behavior Tells Us about Business Cycles." American Economic Review 90, no. 3 (June): 458-81.

[2] Carlton, D., 1983. "Equilibrium Fluctuations when Price and Delivery Lag Clear the Market," The Bell Journal of Economics, Vol. 14, No. 2, 562-572

[3] Copeland, A., and James Kahn, 2011. "The Production Impact of Cash for Clunkers: Implications for Stabilization Policy." Federal Reserve Bank of New York Staff Reports No. 503 (forthcoming, Economic Inquiry).

[4] Copeland, Adam, and George Hall. 2011. "The Response of Prices, Sales, and Output to Temporary Changes in Demand." Journal of Applied Econometrics 26, no. 2 (March): 232-269.

[5] Dixit, A. and J. Stiglitz, 1977. "Monopolistic Competition and Optimum Product Diversity," The American Economic Review, Vol. 67, No. 3, 297-308

[6] Froot, K. and P. Klemperer, 1989. "Exchange Rate Pass-Through When Market Share Matters," The American Economic Review Vol. 79, No. 4, 637-654

[7] Goldberg, P. and F. Verboven, 2001. "The Evolution of Price Dispersion in the European Car Market," Review of Economic Studies Vol. 68, No. 4, 811-848.

[8] Goldberg, P. and M. Knetter, 1997. "Goods Prices and Exchange Rates: What Have We Learned?" Journal of Economic Literature 35, 1243-1272.

[9] Hellerstein, R., 2008. "Who Bears the Cost of a Change in the Exchange Rate? Passthrough Accounting for the Case of Beer," Journal of International Economics 76, $14-32$.

[10] Hooper, P., and C. Mann, 1989. "Exchange Rate Pass-through in the 1980s: The Case of U.S. Imports of Manufactures, Brookings Papers on Economic Activity 1: 297-337. 
[11] Kahn, J.,1987. "Inventories and the Volatility of Production." American Economic Review 77, no. 4 (September): 667-79.

[12] Kahn, J., 1992. "Why Is Production More Volatile than Sales? Theory and Evidence on the Stockout-Avoidance Motive for Inventory-Holding." Quarterly Journal of Economics 107, no. 2 (May): 481-510.

[13] Kahn, J., 2008. "Durable Goods Inventories and the Great Moderation." Federal Reserve Bank of New York Staff Reports No. 325.

[14] Krugman, P.R., 1987. Pricing to market when the exchange rate changes, in: SW. Amdt and J.D. Richardson, eds., Real-financial linkages among open economies (MIT Press, Cambridge, MA).

[15] Maccini, L. 1973. "On Optimal Delivery Lags," Journal of Economic Theory 6, 107-125.

[16] Mann, C., 1986. Prices, profit margins and exchange rates, Federal Reserve Bulletin 72, 366-379.

[17] Marston, R., 1990. "Pricing to market in Japanese manufacturing," Journal of International Economics, Vol. 29, Nos. 3-4, 217-236 